\title{
Clinical profile, management, and outcome in patients with out of hospital cardiac arrest: insights from a 20-year registry
}

This article was published in the following Dove Press journal:

International Journal of General Medicine

10 July 2014

Number of times this article has been viewed

\author{
Ashfaq Ahmad Patel \\ Abdul Rahman Arabi \\ Hakam Alzaeem \\ Jassim Al Suwaidi \\ Rajvir Singh \\ Hajar A Al Binali \\ Department of Cardiology, \\ Heart Hospital, Hamad Medical \\ Corporation, Doha, Qatar
}

Correspondence: Abdul Rahman Arabi Department of Cardiology, Heart Hospital, Hamad Medical Corporation, PO Box 3050, Doha, Qatar

Tel +974 44395354

Fax+974 44443447

Email abdarabi@yahoo.com
Background: There is limited information regarding the clinical characteristics and outcome of out of hospital cardiac arrest (OHCA) in Middle Eastern patients. The aim of this study was to evaluate clinical characteristics, treatment, and outcomes in patients admitted following OHCA at a single center in the Middle East over a 20 -year period.

Methods: The data used for this hospital-based study were collected for patients hospitalized with OHCA in Doha, Qatar, between 1991 and 2010. Baseline clinical characteristics, in-hospital treatment, and outcomes were studied in comparison with the rest of the admissions.

Results: A total of 41,453 consecutive patients were admitted during the study period, of whom 987 (2.4\%) had a diagnosis of OHCA. Their average age was $57 \pm 15$ years, and $72.7 \%$ were males, $56.5 \%$ were Arabs, and $30.9 \%$ were South Asians. When compared with the rest of the admissions taken as a reference, patients with OHCA were more likely to have diabetes mellitus ( $42.8 \%$ versus $39.1 \%$, respectively, $P=0.02)$, prior myocardial infarction $(21.8 \%$ versus $19.2 \%, P=0.04)$, and chronic renal failure $(7.4 \%$ versus $3.9 \%, P=0.001)$, but were less likely to have dyslipidemia ( $16.9 \%$ versus $25.4 \%, P=0.001$ ). Further, $52.6 \%$ of patients had preceding symptoms, the most common of which was chest pain $(27.2 \%)$ followed by dyspnea $(24.8 \%)$. An initially shockable rhythm (ventricular fibrillation or ventricular tachycardia) was present in $25.1 \%$ of OHCA patients, with ST segment elevation myocardial infarction documented in $30.0 \%$. Severely reduced left ventricular systolic function (ejection fraction $\leq 35 \%$ ) was present in $53.2 \%$ of OHCA patients; $42.9 \%$ had cardiogenic shock requiring use of inotropes at presentation. An intra-aortic balloon pump was inserted in $3.6 \%$ of cases. Antiarrhythmic medications were used in $27.4 \%$ and thrombolytic therapy in $13.9 \%$, and $10.8 \%$ underwent a percutaneous coronary procedure (coronary angiography \pm percutaneous coronary intervention). The in-hospital mortality rate was $59.8 \%$.

Conclusion: OHCA was associated with higher incidences of diabetes, prior myocardial infarction, and chronic kidney disease as compared with the remaining admissions. Approximately half of the patients had no preceding symptoms. In-hospital mortality was high (59.8\%), but similar to the internationally published data.

Keywords: out of hospital cardiac arrest, cardiogenic shock, in-hospital mortality

\section{Introduction}

The worldwide incidence of sudden cardiac death (SCD) is difficult to estimate because numbers vary according to the prevalence of coronary heart disease in different countries. ${ }^{1}$ In the USA, the overall incidence of SCD in the general population is estimated to be $0.1 \%-0.2 \%$ per year. $^{2}$ There is an age-related increase in risk of SCD over time, given that the prevalence of coronary heart disease increases as a function of increasing age. ${ }^{2} \mathrm{SCD}$ is more common in men than in women during 
young adulthood and in early middle age. However, the risk of a coronary event increases in post-menopausal women, and the SCD risk increases proportionately, with similar rates in men and women. ${ }^{3}$

Disease of the coronary arteries and its consequences account for at least $80 \%$ of SCD in Western countries, and the nonischemic cardiomyopathies account for a further $10 \%-15 \%{ }^{3} \mathrm{SCD}$ is responsible for half of all cardiovascular deaths in the USA, and for SCD due to coronary heart disease, up to half are first clinical events. ${ }^{2,4}$ An ejection fraction $\leq 30 \%$ is the single most powerful independent predictor of SCD, but has low sensitivity and specificity. ${ }^{5}$

Approximately $92 \%$ of people who experience an out of hospital cardiac arrest (OHCA) will die. ${ }^{6}$ The survival rate on hospital admission was reported to be $26.3 \%$, with an overall survival rate until hospital discharge of $9.6 \%{ }^{7}$ Although there has been wide variation in rates of survival until hospital discharge for comatose patients admitted after successful resuscitation from $\mathrm{OHCA}, 8,9$ it has been shown that, despite decades of research, the median survival to hospital discharge is poor $(7.9 \%)$ and has remained virtually unchanged for three decades. ${ }^{4,10}$

There is limited information regarding OHCA in Middle Eastern patients. Qatar is a small country with a rapidly growing population and a unique age and sex distribution. In view of its unusual population demographics, the purpose of our study was to evaluate the clinical characteristics, treatment, and outcomes in patients with OHCA admitted to a single center in the state of Qatar over the past 20 years.

\section{Materials and methods Study population and case definition}

This was a retrospective study of patients with OHCA admitted over a 20-year period to the Department of Cardiology, Hamad Medical Corporation, Doha, Qatar. This is a large public hospital providing inpatient and outpatient medical and surgical care to the entire population of Qatar. It is estimated that more than $95 \%$ of cardiac patients in the region are treated in this hospital. During the study period, all patients with OHCA were admitted to Hamad General Hospital.

The State of Qatar is located on the Arabian Peninsula, and had a total population estimated at 1,699,435 in 2010. ${ }^{11}$ Arabs (40\%) were the largest ethnic group, followed by Indian (18\%), Pakistani (18\%), Iranian (10\%), and other (14\%). ${ }^{12}$ The male to female ratio was 3.1 to $1.0 .{ }^{11}$

The cardiology database at Hamad General Hospital was used for this study. Data are entered on all patients admitted with a cardiac illness to Hamad General Hospital. A dedicated report form with a specific identification registration number for each patient admitted to the hospital with a cardiac condition is filled out by the assigned physician, who follows the patient throughout his/her hospital stay and completes the form before the patient's discharge from hospital. Data are collected from each patient's medical records at the time of discharge according to predefined criteria for each variable. These records have been coded and registered at the Department of Cardiology since January 1991.

This investigation was approved by the Hamad Medical Corporation ethics committee. It was an observational study spanning a 20-year period (1991-2010) and the data were analyzed anonymously. Using the prescribed database, all patients admitted with a diagnosis of OHCA were retrospectively identified by selecting all patients labeled as "cardiac arrest", "ventricular fibrillation", or "asystole", or a combination of these, under the heading of "admission diagnosis", and their data were analyzed for clinical characteristics, treatment, and in-hospital outcome, and then compared with the rest of the cardiac patients in the registry ("noncardiac arrest"), taken as reference.

\section{Definitions}

OHCA was defined as cessation of mechanical cardiac activity that occurred outside of the hospital setting and confirmed by the absence of signs of circulation. ${ }^{6,13}$ The study population consisted of adult patients who suffered an OHCA and were successfully resuscitated with return of spontaneous circulation. Only those with OHCA of presumed cardiac etiology and admitted to the Department of Cardiology were included in this study. Patients with OHCA who died at the scene, during transportation to hospital, in the emergency room prior to admission to the cardiac unit, or were dead on arrival were excluded, along with those who had OHCA secondary to noncardiac causes, such as respiratory failure, a metabolic disorder, drug overdose, burns, drowning, or trauma.

ST segment elevation myocardial infarction (STEMI) was defined as the presence of ST elevation on a post return of spontaneous circulation electrocardiogram (ECG) irrespective of symptoms and/or cardiac markers (some patients' symptoms were unknown and some died before the results of cardiac markers could be obtained). The presence of hypertension was determined by any documentation in the medical record of hypertension or if the patient was being treated for hypertension by a physician. The presence of 
diabetes was determined by documentation in the patient's previous or current medical record of a diagnosis of diabetes mellitus that had been treated with medications and/or insulin. Chronic renal impairment was defined as creatinine $>1.5$ times the upper limit of the normal range. The presence of hyperlipidemia was determined by demonstration of a fasting cholesterol $>5.2 \mathrm{mmol} / \mathrm{L}$ in the patient's medical record, or any history of treatment for hyperlipidemia by a physician. Congestive heart failure was defined using the Framingham criteria. ${ }^{14}$

\section{Statistical analysis}

Data were presented as the mean \pm standard deviation and median with interquartile range for interval variables and as the frequency and percentage for categorical variables. Baseline demographic characteristics, past medical history, clinical presentation, medical therapy, cardiac procedures, and clinical outcomes were compared between the OHCA and non-OHCA groups using independent Student's $t$-tests and chi-squared tests for interval and categorical variables, respectively. Variables influencing in-hospital mortality were assessed using univariate logistic regression. Risk factors along with other modified variables significant at the univariate level were considered for multivariate logistic regression analysis. Adjusted odds ratios, $95 \%$ confidence intervals, and $P$-values are reported for predictors. All $P$-values are the result of two-tailed tests, and values $<0.05$ were considered to be statistically significant. Statistical Package for Social Sciences version 19.0 software (SPSS Inc., Chicago, IL, USA) was used for the analysis.

\section{Results}

\section{Study population}

A total of 41,453 patients were hospitalized with an acute cardiac disorder between January 1991 and the end of 2010, of whom 987 (2.4\%) were admitted with a diagnosis of OHCA.

\section{Baseline clinical characteristics}

The baseline patient demographics are outlined in Table 1 and the baseline clinical characteristics in Table 2. Patients with OHCA were older (mean age $57 \pm 15$ years versus $53 \pm 13$ years, $P=0.001)$ with more females $(27.3 \%$ versus $23.5 \%, P=0.005$ ) as compared with the non-OHCA group. The age distribution is shown in Figure 1. The majority of the OHCA patients were aged 51-65 years (37.1\%), with few younger than 35 years $(7.5 \%)$. The majority were of
Table I Patient demographics

\begin{tabular}{llll}
\hline $\begin{array}{l}\text { Patient } \\
\text { characteristics }\end{array}$ & $\begin{array}{l}\text { OHCA } \\
\text { group }\end{array}$ & $\begin{array}{l}\text { Non-OHCA } \\
\text { group }\end{array}$ & P-value \\
\hline $\begin{array}{l}\text { Number (\%) } \\
\text { Age (years) }\end{array}$ & $987(2.4 \%)$ & $40,466(97.6 \%)$ & \\
$\begin{array}{l}\text { Sex, female } \\
\text { Age group, years }\end{array}$ & 27.3 & $54 \pm 13$ & 0.001 \\
$\quad<35$ & 7.5 & 23.5 & 0.005 \\
$\quad 35-50$ & 26.1 & 6.7 & \\
5 I-65 & 37.1 & 34.7 & \\
$\quad>65$ & 29.3 & 39.1 & \\
Race & & 19.4 & \\
$\quad$ Arab & 56.5 & 54.9 & \\
$\quad$ South Asian & 30.9 & 33.6 & 0.18 \\
$\quad$ Other & 12.6 & 11.5 & \\
\hline
\end{tabular}

Abbreviation: OHCA, out of hospital cardiac arrest.

Arab (56.5\%) followed by South Asian (30.9\%) ethnicity. There was no significant difference in racial distribution between the OHCA and non-OHCA groups $(P=0.18)$. When compared with the non-OHCA group, the OHCA group had a higher risk profile overall. The incidence of diabetes ( $42.8 \%$ versus $39.1 \%, P=0.02$ ), history of previous myocardial infarction $(21.8 \%$ versus $19.2 \%, P=0.04)$ and chronic renal failure $(7.4 \%$ versus $3.9 \%, P=0.001)$ were more prevalent in the OHCA group, whereas dyslipidemia was more common in the non-OHCA group (16.9\% versus $25.4 \%, P \leq 0.001)$.

\section{Preceding symptoms}

Preceding symptoms were documented in $52.6 \%$ of OHCA patients. The two most common symptoms were chest pain and dyspnea, with an incidence of $27.2 \%$ and $24.8 \%$, respectively.

\section{Preadmission medication}

Patients with OHCA were less likely to have been on any cardiac $(18.6 \%$ versus $22.6 \%, P=0.003)$ or antithrombotic (32.9\% versus $35.7 \%, P=0.03$ ) medication prior to the event.

\section{Cardiac rhythm}

An initial shockable rhythm (ventricular tachycardia/ ventricular fibrillation) was present in $25.1 \%$ and asystole was present in $13.2 \%$ of the OHCA patients. The initial rhythm was unknown in $45.2 \%$ of patients.

\section{ST segment elevation myocardial infarction}

Thirty percent of the OHCA group had STEMI as compared with $17.4 \%$ of the non-OHCA group $(P=0.001)$. 
Table 2 Baseline characteristics and clinical outcomes in study population

\begin{tabular}{|c|c|c|c|}
\hline Patient characteristics & $\begin{array}{l}\text { OHCA } \\
\text { group (\%) }\end{array}$ & $\begin{array}{l}\text { Non-OHCA } \\
\text { group (\%) }\end{array}$ & $P$-value \\
\hline \multicolumn{4}{|l|}{ Risk factors } \\
\hline Diabetes & 42.8 & 39.1 & 0.02 \\
\hline Hypertension & 42.7 & 40.6 & 0.19 \\
\hline FH of IHD & 1.7 & 1.9 & 0.67 \\
\hline Prior MI & 21.8 & 19.2 & 0.04 \\
\hline Prior cardiac surgery & 5.6 & 6.0 & 0.75 \\
\hline CRF & 7.4 & 3.9 & 0.001 \\
\hline Smoker & 19.9 & 22.3 & 0.07 \\
\hline Dyslipidemia* & 16.9 & 25.4 & 0.001 \\
\hline $\begin{array}{l}\text { Obesity (defined as } \\
\text { BMI }>30 \text { ) }\end{array}$ & 28.2 & 30.6 & 0.47 \\
\hline \multicolumn{4}{|l|}{ Preceding symptoms } \\
\hline Chest pain & 27.2 & 47.0 & 0.001 \\
\hline Dyspnea & 24.8 & 22.5 & 0.09 \\
\hline Palpitations & 3.3 & 8.7 & 0.001 \\
\hline Dizziness & 2.5 & 3.8 & 0.03 \\
\hline Noncardiac complaint & 3.0 & 2.0 & 0.02 \\
\hline $\begin{array}{l}\text { Unknown or no preceding } \\
\text { symptoms }\end{array}$ & 47.4 & 25.9 & 0.001 \\
\hline \multicolumn{4}{|l|}{ Preadmission medications } \\
\hline Antiarrhythmics & 7.1 & 6.5 & 0.42 \\
\hline Beta-blockers & 7.5 & 10.9 & 0.001 \\
\hline Calcium channel blocker & 3.2 & 4.6 & 0.05 \\
\hline ACEI/ARB & 7.4 & 9.9 & 0.009 \\
\hline Any cardiac medication & 18.6 & 22.6 & 0.003 \\
\hline Antithrombotic medication & 32.9 & 35.7 & 0.03 \\
\hline \multicolumn{4}{|l|}{ (ASA/clopidogrel) } \\
\hline \multicolumn{4}{|l|}{ ECG } \\
\hline \multicolumn{4}{|l|}{ Initial rhythm } \\
\hline Asystole & 13.2 & 0.0 & 0.001 \\
\hline VT/VF (shockable rhythm) & 25.1 & 1.3 & 0.001 \\
\hline Unknown rhythm & 45.2 & 25.1 & 0.001 \\
\hline Others & 9.4 & 12.3 & 0.001 \\
\hline STEMI & 30.0 & 17.4 & 0.001 \\
\hline \multicolumn{4}{|c|}{ Laboratory values (mean $\pm S D$ ) } \\
\hline $\mathrm{Hb}(\mathrm{g} / \mathrm{dL})$ & $12.6 \pm 2.6$ & $13.0 \pm 2.2$ & 0.02 \\
\hline $\mathrm{RBC}(\mathrm{mmol} / \mathrm{L})$ & $10.7 \pm 6.1$ & $8.4 \pm 4.6$ & 0.001 \\
\hline Creatinine & $143.8 \pm 107.5$ & $101.1 \pm 73$ & 0.001 \\
\hline Cholesterol (mmol/L) & $4.6 \pm 1.5$ & $4.9 \pm 1.3$ & 0.001 \\
\hline $\mathrm{HDL}(\mathrm{mmol} / \mathrm{L})$ & $1.0 \pm 0.4$ & $1.0 \pm 0.3$ & 0.41 \\
\hline LDL (mmol/L) & $2.7 \pm 1.3$ & $2.8 \pm 1.1$ & 0.21 \\
\hline $\mathrm{TG}(\mathrm{mmol} / \mathrm{L})$ & $1.7 \pm 1.0$ & $1.9 \pm 1.2$ & 0.001 \\
\hline CPK (peak) & $4,202 \pm 11,322$ & & \\
\hline CKMB (peak) & $243 \pm 758$ & & \\
\hline \multicolumn{4}{|l|}{ LV function } \\
\hline Mean EF (\%) & $35 \pm 13$ & $43 \pm 13$ & 0.001 \\
\hline$<25$ & 29.1 & 10.8 & \\
\hline $25-35$ & 24.1 & 17.8 & \\
\hline $36-45$ & 26.1 & 23.5 & \\
\hline$>45$ & 20.6 & 48.0 & 0.001 \\
\hline \multicolumn{4}{|l|}{ Hospital stay, days } \\
\hline Mean total stay & $6.4 \pm 6.2$ & $4.6 \pm 3.7$ & 0.001 \\
\hline Median & $4(2-9)$ & $4(I-4)$ & \\
\hline
\end{tabular}

Note: *Defined as cholesterol higher than $5.17 \mathrm{mmol} / \mathrm{L}$ and/or TG more than $1.7 \mathrm{mmol} / \mathrm{L}$. Abbreviations: $A C E I$, angiotensin-converting enzyme inhibitor; $A R B$, angiotensin receptor blocker; ASA, acetylsalicylic acid; BMI, body mass index; CKMB, creatine kinase $\mathrm{MB}$; CPK, creatine phosphokinase; CRF, chronic renal failure; ECG, electrocardiogram; $E F$, ejection fraction; $F H$, family history; $H b$, hemoglobin; $H D L$, high-density lipoprotein cholesterol; IHD, ischemic heart disease; LDL, low-density lipoprotein cholesterol; LV, left ventricular; MI, myocardial infarction; OHCA, out of hospital cardiac arrest; RBC, red blood cells; SD, standard deviation; STEMI, ST segment elevation myocardial infarction; TG, triglycerides; VT, ventricular tachycardia; VF, ventricular fibrillation.

\section{Laboratory parameters}

On admission, patients in the OHCA group had higher random blood sugar $(10.7 \pm 6.1 \mathrm{mmol} / \mathrm{L}$ versus $8.4 \pm 4.6 \mathrm{mmol} / \mathrm{L}$, $P=0.001)$ and serum creatinine levels $(143.8 \pm 107.5 \mu \mathrm{mol} / \mathrm{L}$ versus $101.1 \pm 73 \mu \mathrm{mol} / \mathrm{L}, P=0.001)$, but lower total cholesterol $(4.6 \pm 1.5 \mathrm{mmol} / \mathrm{L}$ versus $4.9 \pm 1.3 \mathrm{mmol} / \mathrm{L}$, $P=0.001)$ and triglyceride $(1.7 \pm 1.0 \mathrm{mmol} / \mathrm{L}$ versus $1.9 \pm 1.2 \mathrm{mmol} / \mathrm{L}, P=0.001$ ) levels in comparison with the non-OHCA group. The total creatine phosphokinase rise in absolute terms in patients with STEMI in the OHCA group was significantly higher than in patients with STEMI in the non-OHCA group $(7,554 \pm 16,550 \mathrm{IU} / \mathrm{L}$ versus $2,412 \pm 2,759$ $\mathrm{IU} / \mathrm{L}, P=0.001)$. Although the difference in creatine kinase MB elevation did not reach statistical significance, it showed a similar trend $(441 \pm 1,124 \mathrm{IU} / \mathrm{L}$ versus $331 \pm 897 \mathrm{IU} / \mathrm{L}$, $P=0.07)$.

\section{Left ventricular systolic function}

Left ventricular systolic function was assessed by two-dimensional echocardiography after return of spontaneous circulation, and was found to be significantly reduced in the OHCA group when compared with the non-OHCA group $(35 \% \pm 13 \%$ versus $43 \% \pm 13 \%, P<0.001)$. Severe left ventricular dysfunction (ejection fraction $\leq 35 \%$ ) was observed in $53.2 \%$ of the OHCA group, and $20.6 \%$ had preserved left ventricular systolic function (ejection fraction $>45 \%$ ).

\section{Length of stay}

OHCA patients had an average total hospital stay of $6.4 \pm 6.2$ days as compared with $4.6 \pm 3.7$ days $(P=0.001)$ for the non-OHCA patients. Both coronary care unit stay (3.9 \pm 2.7 days) and total hospital stay (7.5 \pm 6.0 days) were significantly prolonged in OHCA patients who survived compared with that in those who did not $(2.0 \pm 2.3$ days versus $5.2 \pm 6.2$ days, respectively).

\section{Temporal trend}

The temporal trend for the incidence of OHCA is shown in Figure 2. The number of OHCA patients steadily increased over time, both in absolute (Figure 2) and relative (19.7\%, $22.1 \%, 27.2 \%$, and $31.1 \% ; P=0.03$ ) terms. However, in relation to population growth, the incidence actually decreased, with $31.1 \%$ of all OHCA patients admitted during the last 5 years as compared with $19.7 \%$ during the first 5 years of the study $(P=0.03)$. However, this remained relatively constant in proportion to the total in-hospital admissions and averaged 2.3\%. With regard to age group, 


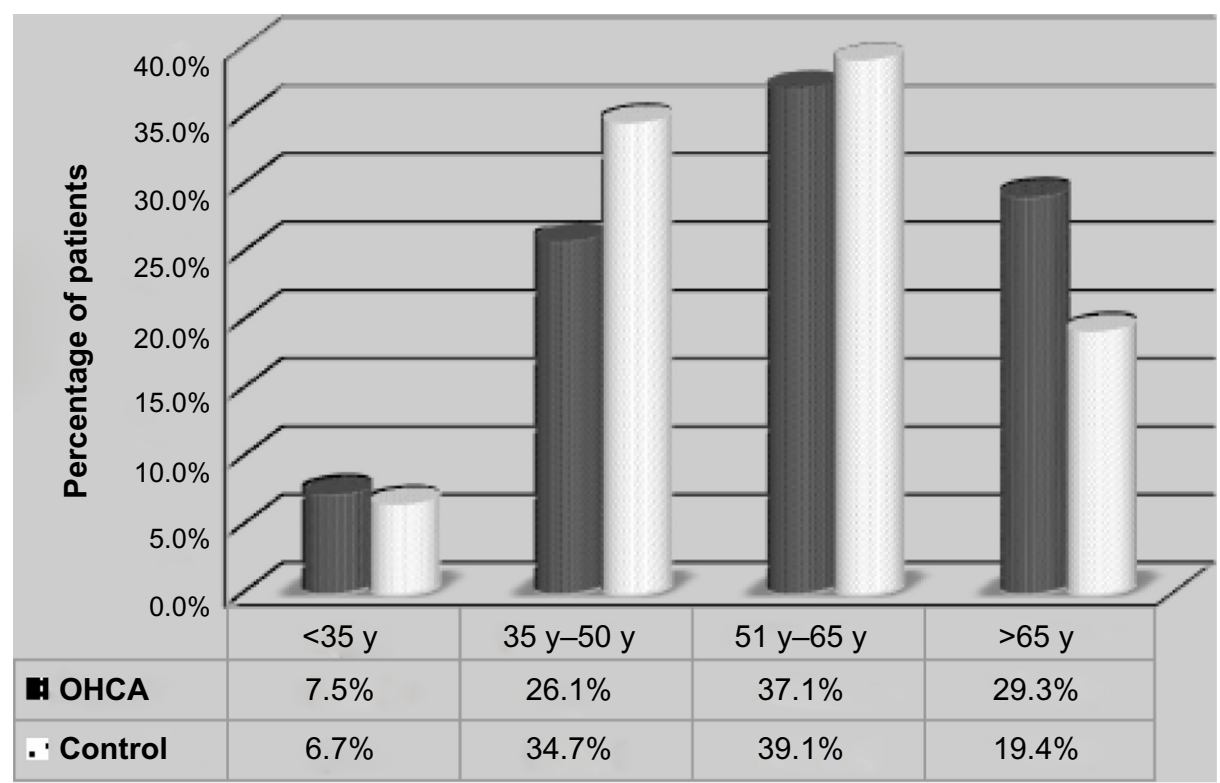

Figure I Age distribution for out of hospital cardiac arrest.

Abbreviations: OHCA, out of hospital cardiac arrest; $y$, years.

there were significantly more patients aged $35-50$ years in the latter half of the study in comparison with the first half $(16.0 \%$ versus $10.1 \%, P=0.003)$. There was no significant trend in the remaining age groups over time. The

A

\section{Incidence}

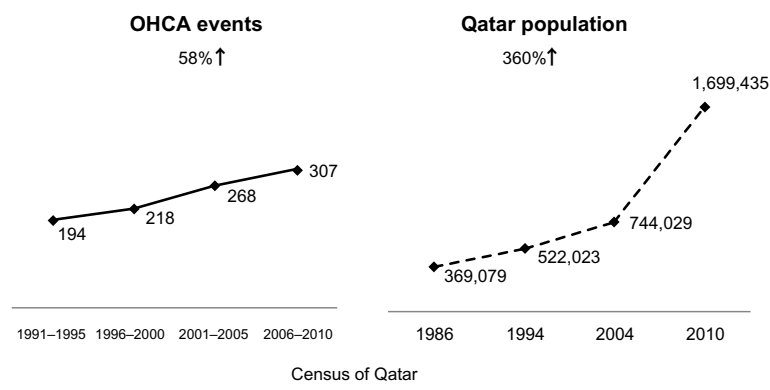

\section{B Temporal trends in OHCA incidence}

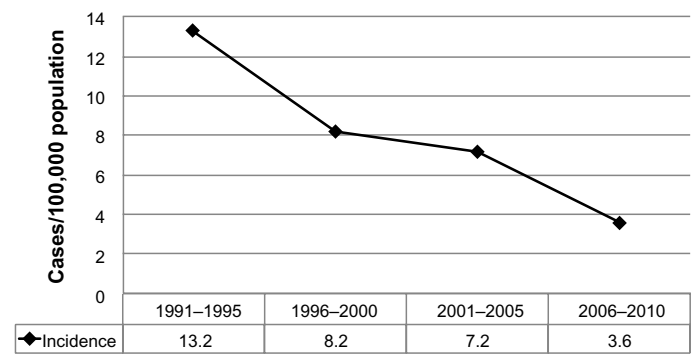

Figure 2 (A) Incidence and (B) temporal trends for out of hospital cardiac arrest. Abbreviation: OHCA, out of hospital cardiac arrest. relative proportion of female patients peaked at $33.9 \%$ in the OHCA group in the second quarter (1996-2000) of the study $(P=0.03)$.

\section{In-hospital management}

The data for in-hospital management are summarized in Table 3. Antiarrhythmic medications were prescribed in $27.4 \%$ of the OHCA group versus $13.6 \%$ in the non-OHCA group $(P=0.001)$. Use of inotropes was significantly greater in the OHCA group ( $42.9 \%$ versus $6.0 \%, P=0.001$ ). Conversely, proportionately fewer patients in the OHCA group were given beta-blockers $(15.2 \%$ versus $34.9 \%, P=0.001)$, calcium channel blockers ( $4.0 \%$ versus $12.6 \%, P=0.001)$, or angiotensin-converting enzyme inhibitors/angiotensin receptor blockers $(18.2 \%$ versus $30.9 \%, P=0.001)$, likely because of their hemodynamic instability. Fewer patients in the OHCA group were treated with antiplatelet or antithrombotic therapy as compared with the non-OHCA group (53.5\% versus $76.1 \%$ [ $P=0.001]$ for aspirin; $12.6 \%$ versus $18.4 \%[P=0.001]$ for clopidogrel; and $33.7 \%$ versus $41.2 \%$ $[P=0.001]$ for anticoagulation therapy). Insertion of an intraaortic balloon pump ( $3.6 \%$ versus $0.3 \%, P=0.001$ ), invasive hemodynamic monitoring (6.6\% versus $0.6 \%, P=0.001)$, and temporary pacemaker insertion $(6.0 \%$ versus $0.9 \%$, $P=0.001$ ) were more frequent in the OHCA group than in the non-OHCA group.

Overall, 10.8\% of OHCA patients underwent an invasive coronary procedure in the cardiac catheterization laboratory, $6.7 \%$ underwent percutaneous coronary intervention, $1.9 \%$ 
Table 3 Treatment received

\begin{tabular}{llll}
\hline & $\begin{array}{l}\text { OHCA } \\
\text { group (\%) }\end{array}$ & $\begin{array}{l}\text { Non-OHCA } \\
\text { group (\%) }\end{array}$ & P-value \\
\hline Medications & & & \\
Antiarrhythmics & 27.4 & 13.6 & 0.001 \\
Beta-blockers & 15.2 & 34.9 & 0.001 \\
Calcium channel blockers & 4.0 & 12.6 & 0.001 \\
ACEI/ARB & 18.2 & 30.9 & 0.001 \\
ASA & 53.5 & 76.1 & 0.001 \\
Clopidogrel & 12.6 & 18.4 & 0.001 \\
Anticoagulation* & 33.7 & 41.2 & 0.001 \\
Inotropes & 42.9 & 6.0 & 0.001 \\
Furosemide & 26.8 & 26.9 & 0.98 \\
Thrombolytic treatment & 13.9 & 12.6 & 0.22 \\
Percutaneous procedures & & & \\
Swan Ganz & 6.6 & 0.6 & 0.001 \\
Any PCI** & 6.7 & 6.1 & 0.42 \\
PCl on admission (emergency) & 1.9 & 0.6 & 0.001 \\
Any coronary procedure*** & 10.8 & 16.7 & 0.001 \\
Temporary pacer & 6.0 & 0.9 & 0.001 \\
Device-based therapy $\$ 5$ & 1.2 & 0.9 & 0.33 \\
IABP & 3.6 & 0.3 & 0.001 \\
Cardiac surgery & 0.6 & 0.7 & 0.73 \\
Mortality & 59.8 & 3.4 & 0.001 \\
\hline Notes & &
\end{tabular}

Notes: *Heparin or low molecular weight heparin; **PCl on admission or anytime during in-hospital stay; ***coronary angiography $\pm \mathrm{PCl}$; ${ }^{\delta \S}$ permanent pacemaker/ CRT/AICD implantation; sinotropes include dopamine, dobutamine, adrenaline, and noradrenaline.

Abbreviations: AICD, automatic implantable cardioverter defibrillator; CRT, cardiac resynchronization therapy; ACEI, angiotensin-converting enzyme inhibitor; ARB, angiotensin receptor blocker; ASA, acetylsalicylic acid; OHCA, out of hospital cardiac arrest; $\mathrm{PCl}$, percutaneous coronary intervention; IABP, intra-aortic balloon pump.

underwent emergency percutaneous coronary intervention on admission (representing 5.7\% of STEMIs in the OHCA group), and $13.9 \%$ were treated with thrombolytic therapy (representing $46.3 \%$ of STEMIs in the OHCA group). There was no significant difference in use of device-based therapy $(1.2 \%$ versus $0.9 \%, P=0.33)$ or cardiac surgery $(0.6 \%$ versus $0.7 \%, P=0.73)$.

\section{Outcome}

The rate of survival until discharge from hospital was $40.2 \%$. Survival was defined irrespective of neurological outcome.

\section{Trend of outcomes}

Table 4 shows the trends in terms of incidence, age distribution, and in-hospital mortality. Over a period of 20 years, in-hospital mortality peaked in the third quarter of the study period (2001-2005) at $67.5 \%$ and was lowest in the first quarter (1991-1995) at 43.8\% ( $P=0.001)$. Duration of hospital stay did not show any significant differences during the study period.

\section{Multiple logistic regression analysis}

Following adjustment for other variables, multivariate analysis showed that age $\geq 50$ years, diabetes mellitus, cardiogenic shock, and chronic kidney disease were independent predictors of increased in-hospital mortality, whereas STEMI, reperfusion therapy, presence of a shockable rhythm, and witnessed OHCA were predictors of increased likelihood of survival (Figure 3). It must be noted that, although significant in univariate analysis, an ejection fraction $>35 \%$ was not included in multivariate analysis because data on ejection fraction were available for only $20 \%$ of the study group.

\section{Discussion \\ Clinical characteristics}

The mean age at cardiac arrest in our study was younger ( $57 \pm 15$ years) than that in a previous report from the USA (64.0 \pm 18.2 years) but had a similar male predominance. ${ }^{7}$ It is well established that the incidence of cardiac arrest increases dramatically with increasing age in both men and women, although the incidence of sudden death is higher in men than in women, ${ }^{15}$ with men being $2-3$ times more likely to experience sudden cardiac arrest than women. Similar

Table 4 Temporal trend of OHCA patients

\begin{tabular}{|c|c|c|c|c|c|}
\hline OHCA & $|99|-\mid 995$ & $1996-2000$ & $200 I-2005$ & $2006-2010$ & $P$-value \\
\hline $\mathrm{n}(\%$ of $\mathrm{OHCA})$ & $194(19.7)$ & $218(22.1)$ & $268(27.2)$ & $307(31.1)$ & 0.03 \\
\hline n (\% of total admissions) & $194(2.1)$ & $218(2.3)$ & $268(2.7)$ & $307(2.3)$ & 0.03 \\
\hline Female (\%) & $46(23.7)$ & $74(33.9)$ & $78(29.1)$ & $71(23.1)$ & 0.03 \\
\hline \multirow{2}{*}{\multicolumn{6}{|c|}{ Number by age group }} \\
\hline & & & & & $(\%$ of $\mathrm{OHCA})$ \\
\hline Age $<35$ years & $23(2.3)$ & $13(1.3)$ & $10(1.0)$ & $28(2.8)$ & 0.21 \\
\hline Age $35-50$ years & $52(5.3)$ & $47(4.8)$ & $79(8.0)$ & $79(8.0)$ & 0.003 \\
\hline Age $5 \mathrm{I}-65$ years & $72(7.3)$ & $84(8.5)$ & $99(10.0)$ & $110(11.2)$ & 0.42 \\
\hline Age $>65$ years & $47(4.8)$ & $74(7.5)$ & $78(7.9)$ & $90(9.1)$ & 0.5 \\
\hline Mortality rate (\%) & $85(43.8)$ & I $46(67.0)$ & |8| (67.5) & I $78(58.0)$ & 0.001 \\
\hline
\end{tabular}

Note: Data are expressed as absolute numbers (percentages).

Abbreviation: OHCA, out of hospital cardiac arrest. 


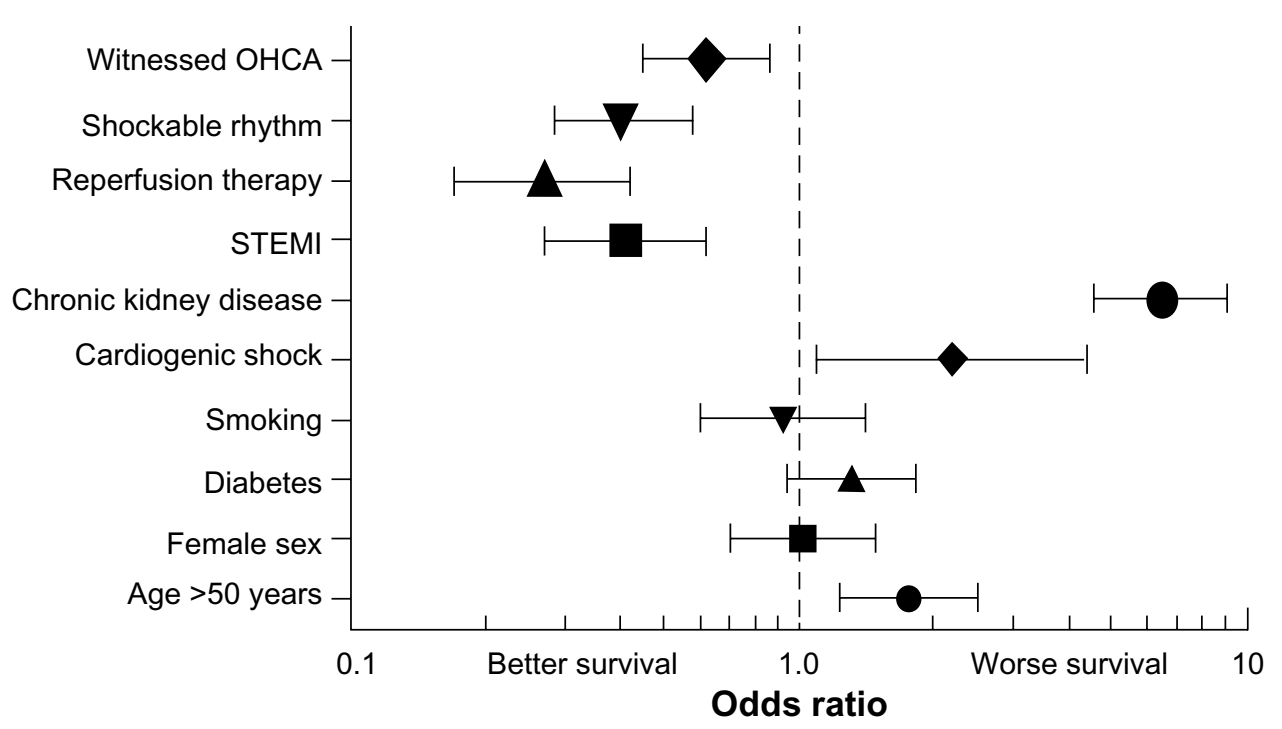

Figure 3 Multivariate analysis of predictors of survival.

Abbreviations: OHCA, out of hospital cardiac arrest; STEMI, ST segment elevation myocardial infarction.

findings were demonstrated in our study. It is well recognized that patients with established heart disease or significant risk factors for coronary heart disease have a significantly higher incidence of SCD. ${ }^{16,17}$ Similarly, the OHCA patients in our study population had a high risk profile, as demonstrated by a higher incidence of diabetes mellitus (42.8\%), previous myocardial infarction (21.8\%), and chronic renal failure (7.4\%) compared with non-OHCA patients (Table 2). The incidences of other risk factors were also high, ie, hypertension (42.7\%), obesity (28.2\%), and smoking (19.9\%). The lower prevalence of dyslipidemia in the OHCA group might be explained by the fact that this was a selected population that had been successfully resuscitated and survived long enough to be admitted to hospital. Further, hypercholesterolemia has been shown to be an important risk factor, and to adversely affect the outcome of cardiopulmonary resuscitation. ${ }^{18}$

\section{Trends}

During the 20-year study period, although the absolute number of patients with OHCA increased over time, the incidence per 100,000 population actually decreased (Figure 2). This is explained by the fact that, although the population of Qatar has nearly tripled since 2001 (600,000 population in 2001 and 1.6 million in 2010) ${ }^{11}$ this growth is largely due to the influx of a young healthy workforce to the state of Qatar; this age group is significantly lower than the average age of patients with OHCA at presentation. Moreover, this is a preselected group of healthy individuals who had undergone pre-employment health screening prior to arrival in the country. The decrease in the in-hospital mortality rate in the last quarter (2006-2010) as compared with the period prior (1996-2005) may possibly be explained by the increased use of percutaneous coronary intervention in the latter group (more specifically in those with STEMI), given that this is the only treatment shown to have a beneficial effect on survival. Improvements in multidisciplinary and intensive medical care are also likely contributors to this favorable trend.

\section{Preceding symptoms}

Preceding symptoms were known in 52.6\% of OHCA patients admitted to hospital. This would suggest that at least half of the patients were likely to have had a witnessed OHCA event. It is well documented that those who have had a witnessed OHCA event are more likely to be alive on admission to hospital and have a better prognosis that those with unwitnessed OHCA. ${ }^{7}$

Definite STEMI based on ECG criteria was diagnosed in $30.0 \%$ of patients with OHCA. This is comparable with a previously reported incidence of angiographically defined acute myocardial infarction of $36 \%$ in patients who have suffered an OHCA with sustained return of spontaneous circulation. ${ }^{19}$ It must also be borne in mind that the negative predictive value of ST segment elevation on ECG to rule out an acute coronary event may be low after OHCA. ${ }^{20}$

\section{Treatment}

In our registry, reperfusion therapy (thrombolysis and/or percutaneous coronary intervention) was an independent predictor of improved survival. Similar findings have been reported previously ${ }^{21-23}$ and support early reperfusion therapy 
in initial survivors of OHCA. Primary percutaneous coronary intervention has been shown to be superior to thrombolysis in this setting. ${ }^{21}$

Spaulding et al reported that ECG is an insensitive marker in OHCA patients, and therefore a normal ECG does not rule out an epicardial coronary occlusion. ${ }^{24}$ Indeed, it has been reported that successful immediate coronary angioplasty is associated with improved hospital survival, even in patients without ECG-confirmed STEMI. ${ }^{25}$

There was understandably a significantly higher use of antiarrhythmic $(27.4 \%$ versus $13.6 \%, P=0.001)$ and inotropic $(42.9 \%$ versus $6.0 \%, P=0.001)$ medications in the OHCA group due to the high prevalence of electrical and hemodynamic instability in these patients, given the nature of the event itself. Likewise, and for the same reasons, use of beta-blockers, calcium channel blockers, and angiotensinconverting enzyme inhibitors/angiotensin receptor blockers was significantly less in these patients.

\section{Survival}

In this study, the overall survival rate of patients admitted to hospital after OHCA was 40.2\%, and is comparable with previously reported data. ${ }^{7}$ The most important predictors of improved survival (in decreasing order of weighted importance) were reperfusion therapy, presence of a shockable rhythm, STEMI, and witnessed OHCA. These predictors are similar to those reported previously, ${ }^{26}$ except that in our study male sex was not an independent predictor of increased survival.

A previous study demonstrated that survival until hospital discharge was more likely in patients whose OHCA was witnessed by a bystander or by emergency medical services, and in those who received cardiopulmonary resuscitation from a bystander, were found in ventricular fibrillation/ventricular tachycardia, or achieved return of spontaneous circulation. Approximately one of every four to seven patients with a presenting rhythm of ventricular fibrillation/ventricular tachycardia survive until hospital discharge, compared with only one of every 21 to 500 patients found in asystole. By far the most powerful predictor of survival after OHCA is return of spontaneous circulation in the field. ${ }^{10}$

Published post-OHCA survival rates are very low, averaging $7.6 \% .{ }^{10}$ The neurologically favorable survival rate is even lower and varied between $1.9 \%$ and $3.1 \%$ in Japan. ${ }^{27}$ Survival rates are variable, and vary widely from continent to continent. In Asia, the reported percentage survival to discharge rate is lower (2\%) than in Europe (9\%), North America (6\%), and Australia (11\%). ${ }^{28}$ Within the same continent, it varies from country to country, and may even vary substantially between cities in the same country, due in large part to community differences in the chain of survival. . $^{29,30}$

\section{Limitations of the study}

As in all registry studies spanning long time intervals, policies regarding admission to the coronary care unit and management of OHCA patients would have changed considerably during our study period. Another limitation is that our data were collected and analyzed retrospectively from records registration over 20 years. The fundamental limitations inherent in retrospective observational studies cannot be eliminated and are linked to their nonrandomized nature and unmeasured confounding factors. On the other hand, well designed, retrospective, observational studies may provide valid results without systematic overestimation, bias, or predilection. Finally, no details were available regarding whether the event was witnessed by a bystander or emergency medical services, or whether cardiopulmonary resuscitation was performed by a bystander. Further, no information was available regarding the duration of resuscitation prior to arrival in the emergency room or the neurological status of the patient on arrival or discharge. The outcome in this heterogeneous group of patients will depend on at least some of these unknown variables. Finally, an ambulance service started in 2003, and may have changed the subsequent statistics.

\section{Conclusion}

This study of the clinical characteristics, treatment, and outcomes in OHCA patients admitted to our center in the state of Qatar found a high incidence of coronary risk factors (particularly diabetes and chronic kidney disease) and previous myocardial infarction. Patients admitted with OHCA accounted for $2.4 \%$ of all hospital admissions and had an overall in-hospital mortality rate of $59.8 \%$, similar to what has been reported in the West.

\section{Acknowledgment}

This study was supported by the Medical Research Center of Hamad Medical Corporation.

\section{Disclosure}

The authors report no competing interests in this work.

\section{References}

1. Priori SG, Aliot E, Blomstrom-Lundqvist C, et al. Task Force on Sudden Cardiac Death of the European Society of Cardiology. Eur Heart J. 2001;22:1374-1450.

2. Myerburg RJ. Sudden cardiac death: exploring the limits of our knowledge. J Cardiovasc Electrophysiol. 2001;12:369-381. 
3. Myerburg RJ, Castellanos A. Cardiac arrest and sudden cardiac death. In: Zipes DP, Libby P, Bonow RO, Braunwald E, editors. Braunwald's Heart Disease: A Textbook of Cardiovascular Medicine. 9th ed. Chapter 42.Philadelphia, PA, USA: Saunders Elsevier; 2011.

4. Nichol G, Thomas E, Callaway CW, et al. Regional variation in outof-hospital cardiac arrest incidence and outcome. JAMA. 2008;300: 1423-1431.

5. Myerburg RJ. Implantable cardioverter-defibrillators after myocardial infarction. N Engl J Med. 2008;359:2245-2253.

6. Roger VL, Go AS, Lloyd-Jones DM, et al. Heart disease and stroke statistics - 2011 update: a report from the American Heart Association. Circulation. 2011;123:e18-e209.

7. McNally B, Robb R, Mehta M, et al. Out-of-hospital cardiac arrest surveillance: Cardiac Arrest Registry to Enhance Survival (CARES), United States, October 1, 2005-December 31, 2010. MMWR Surveill Summ. 2011;60:1-19.

8. Herlitz J, Engdahl J, Svensson L, et al. Major differences in 1-month survival between hospitals in Sweden among initial survivors of out-of-hospital cardiac arrest. Resuscitation. 2006;70:404-409.

9. Carr BG, Kahn JM, Merchant RM, et al. Inter-hospital variability in post-cardiac arrest mortality. Resuscitation. 2009;80:30-34.

10. Sasson C, Rogers MA, Dahl J, et al. Predictors of survival from out-of-hospital cardiac arrest: a systematic review and meta-analysis. Circ Cardiovasc Qual Outcomes. 2010;3:63-81.

11. Qatar Statistics Authority. Census 2010. Available from: http://www.qsa. gov.qa/eng/publication/pdf-file/Social/Population_House holds_Establishment_QSA_Census_AE_2010.pdf. Accessed April 11, 2014.

12. US Department of State. US relations with Qatar. Washington, DC, USA: US Department of State; 2013. Available from: http://www.state gov/r/pa/ei/bgn/5437.htm. Accessed April 11, 2014.

13. Jacobs I, Nadkarni V, Bahr J, et al. Cardiac arrest and cardiopulmonary resuscitation outcome reports: update and simplification of the Utstein templates for resuscitation registries: a statement for healthcare professionals from a task force of the International Liaison Committee on Resuscitation (American Heart Association, European Resuscitation Council, Australian Resuscitation Council, New Zealand Resuscitation Council, Heart and Stroke Foundation of Canada, InterAmerican Heart Foundation, Resuscitation Councils of Southern Africa). Circulation. 2004;110:3385-3397.

14. McKee PA, Castelli WP, McNamara PM, et al. The natural history of congestive heart failure: the Framingham study. $N$ Engl J Med. 1971;285:1441-1446.

15. Kannel WB, Wilson PW, D’Agostino RB, Cobb J. Sudden coronary death in women. Am Heart J. 1998;136:205-212.

16. Rea TD, Pearce RM, Raghunathan TE, et al. Incidence of out-of-hospital cardiac arrest. Am J Cardiol. 2004;93:1455-1460.
17. Kuller LH. Sudden death - definition and epidemiologic considerations. Prog Cardiovasc Dis. 1980;23:1-12.

18. Roth A, Golovner M, Gavish D, et al. Medical history of hypercholesterolaemia adversely affects the outcome of out-of-hospital cardiopulmonary resuscitation; the 'Shahal' experience in Israel. Eur Heart J. 2000;21:778-781.

19. Sideris G, Voicu S, Dillinger JG, et al. Value of post-resuscitation electrocardiogram in the diagnosis of acute myocardial infarction in out-ofhospital cardiac arrest patients. Resuscitation. 2011;82:1148-1153.

20. Larsen JM, Løfgren B, Ravkilde J, Krarup NH. [Coronary angiography should be considered after out-of-hospital cardiac arrest]. Ugeskr Laeger. 2011;173:2784-2787. Danish.

21. Bobrow BJ, Kern KB. Regionalization of postcardiac arrest care. Curr Opin Crit Care. 2009;15:221-227.

22. Koeth O, Zahn R, Bauer T, et al. Primary percutaneous coronary intervention and thrombolysis improve survival in patients with ST-elevation myocardial infarction and pre-hospital resuscitation. Resuscitation. 2010;81:1505-1508.

23. Sunde K, Pytte M, Jacobsen D, at al. Implementation of a standardised treatment protocol for post resuscitation care after out-of-hospital cardiac arrest. Resuscitation. 2007;73:29-39.

24. Spaulding CM, Joly LM, Rosenberg A, et al. Immediate coronary angiography in survivors of out-of-hospital cardiac arrest. $N$ Engl J Med. 1997;336:1629-1633.

25. Dumas F, Cariou A, Manzo-Silberman S, et al. Immediate percutaneous coronary intervention is associated with better survival after out-ofhospital cardiac arrest: insights from the PROCAT (Parisian Region Out of hospital Cardiac ArresT) Registry. Circ Cardiovasc Interv. 2010;3: 200-207.

26. Liu JM, Yang Q, Pirrallo RG, Klein JP, Aufderheide TP. Hospital variability of out-of-hospital cardiac arrest survival. Prehosp Emerg Care. 2008;12:339-346.

27. Hasegawa K, Tsugawa Y, Camargo CA Jr, Hiraide A, Brown DF. Regional variability in survival outcomes of out-of-hospital cardiac arrest: The All-Japan Utstein Registry. Resuscitation. 2013;84: 1099-1107.

28. Berdowski J, Berg RA, Tijssen JG, Koster RW. Global incidences of out-of-hospital cardiac arrest and survival rates: Systematic review of 67 prospective studies. Resuscitation. 2010;81:1479-1487.

29. Hiltunen P, Kuisma M, Silfvast T, et al. Regional variation and outcome of out-of-hospital cardiac arrest (OHCA) in Finland - the Finnresusci study. Scand J Trauma Resusc Emerg Med. 2012;20:80.

30. Hess EP, White RD. Optimizing survival from out-of-hospital cardiac arrest. J Cardiovasc Electrophysiol. 2010;21:590-595.
International Journal of General Medicine

\section{Publish your work in this journal}

The International Journal of General Medicine is an international peer-reviewed open-access journal that focuses on general and internal medicine, pathogenesis, epidemiology, diagnosis, monitoring and treatment protocols. The journal is characterized by the rapid reporting of reviews, original research and clinical studies across all disease areas.

\section{Dovepress}

A key focus is the elucidation of disease processes and management protocols resulting in improved outcomes for the patient. The manuscript management system is completely online and includes a very quick and fair peer-review system. Visit http://www.dovepress.com/ testimonials.php to read real quotes from published authors. 